\title{
Erratum to: Isolated cardiac sarcoidosis: A focused review of an under-recognized entity
}

David R. Okada, MD, ${ }^{\mathrm{a}}$ Paco E. Bravo, MD, ${ }^{\mathrm{b}}$ Tomas Vita, $M D,{ }^{\mathrm{c}}$ Vikram Agarwal, MBBS, ${ }^{c}$ Michael T. Osborne, MD, ${ }^{\mathrm{d}}$ Viviany R. Taqueti, MD, MPH, ${ }^{\mathrm{b}}$ Hicham Skali, $M D, M S c,{ }^{b}$ Panithaya Chareonthaitawee, $M D$, e Sharmila Dorbala, $M D, M P H,{ }^{\text {b,c }}$ Garrick Stewart, MD, ${ }^{\mathrm{b}}$ Marcelo Di Carli, $M D,{ }^{\mathrm{b}, \mathrm{c}}$ and Ron Blankstein, $M D^{\mathrm{b}, \mathrm{c}}$

a Division of Cardiology, Department of Medicine, Johns Hopkins Hospital, Baltimore, MD

b Division of Cardiovascular Medicine, Department of Medicine, Brigham and Women's Hospital, Boston, MA

c Department of Radiology, Brigham and Women's Hospital, Boston, MA

d Cardiology Division, Department of Medicine, Massachusetts General Hospital, Boston, MA

e Division of Cardiovascular Diseases, Department of Medicine, Mayo Clinic, Rochester, MN

doi: $10.1007 / \mathrm{s} 12350-016-0688-8$

\section{ERRATUM TO: J NUCL CARDIOL} DOI 10.1007/S12350-016-0658-1

The middle initial of the author "Viviany Taqueti", was missing in the original article. The complete name is "Viviany R. Taqueti". The original article was corrected.

The online version of the original article can be found under doi:10.1007/s12350-016-0658-1.

Reprint requests: Ron Blankstein, MD, Division of Cardiovascular Medicine, Department of Medicine, Brigham and Women's Hospital, 75 Francis St., Boston, MA 02115; rblankstein@partners.org

J Nucl Cardiol 2018;25:1147.

$1071-3581 / \$ 34.00$

Copyright (C) 2016 American Society of Nuclear Cardiology. 